\title{
A study to assess the effectiveness of self instructional module on neonatal care among Primi mothers
}

\author{
*Anoop. $\mathbf{T}$
}

\begin{abstract}
Objectives : To assess the existing level of knowledge and practice of primi mothers regarding neonatal care. To provide self instructional module regarding neonatal care. To assess the effectiveness of SIM regarding knowledge and practice of primi mothers on neonatal care. To determine the association between pre-test knowledge and practices regarding neonatal care with selected demographic variables. Methodology : The researchers approach adapted for the study was pre-experimental using one group pre test post test. Simple random sampling technique was used to select the sample. 50 primi mothers are included in the study. The obtained data was analyzed using descriptive and inferential statistics and interpreted in terms of objectives and hypothesis of the study. Results : in pre-test highest percentage (62\%) of the samples had average knowledge and in post test majority (54\%) of primi mothers were having excellent level of knowledge, and in pre-test highest percentage (64\%) of the samples had average practice scores and in post-test majority (88\%) of primi mother's had good level of practices knowledge Evaluation of the effectiveness of SIM on knowledge and practice regarding new born care shows that the mean post-test knowledge score (22.6) was higher than the mean pretest knowledge scores (14) suggesting that the SIM was effective. Association between pre-test knowledge score and selected demographic variables was found out by using chi square test. The data shows that there was significant association between the per-test knowledge scores and selected demographic variable expect age income, Conclusion: The overall finding of the study clearly showed that the self instructional module was significantly effective in improving the knowledge and practice scores of primi mothers regarding newborn care.
\end{abstract} Key words: Immunization, Breast Feeding, Umbilical Cord, Primi Mothers. 


\section{INTRODUCTION}

The early neonatal period (birth to 7 days) is critical phase in the live of newborn baby. Major changes occur during this period of life which determines the well being of the newborn. Mother has an important role to play in the life of her child.

Every year, four million newborn deaths occur in the world out of which nearly one-fourth are contributed by India. Approximately $98 \%$ of this neonatal mortality takes place in developing countries of the world.

The primary causes of neonatal mortality are complications of prematurity, birth asphyxia, birth injury, neonatal tetanus, congenital anomalies, and diarrhea with low birth weight contributing to a large proportion of deaths. Most of these newborns die at home while being cared by mothers, relatives and traditional birth attendant.

Nearly $50 \%$ of all infant deaths occur during the neonatal period, half of these deaths occur in the first 7 days of life. Due to pre maturity neonatal tetanus, birth asphyxia, and infections which can be prevented by proper and timely care of new born. Therefore, all newborns get home based newborn care as per the perception and socio cultural behavior of the society. However, it has been observed by various studies on the newborn care in the communities that the knowledge and the practices of simple care e.g. prevention of hypothermia, feeding of colostrum and exclusive breastfeeding, are lacking.

\section{PROBLEM STATEMENT:}

A Study To Assess the Effectiveness of Self Instructional Module on Neonatal Care Among primi Mothers

\section{OBJECTIVES:}

1. To assess the existing level of knowledge and practice of primi, mothers regarding neonatal care.

2. To provide SIM regarding Knowledge and practice of primi, mothers regarding neonatal care.

3. To assess the effectiveness of SIM regarding Knowledge and practice of primi, mothers on neonatal care.

4. To determine the association between pre-test knowledge and practices regarding neonatal care with selected demographic variables.

\section{MATERIALS AND METHODS:}

The research approach adapted for the study was pre-experimental, using one group pre test, post design (one group exposed to the pretest and the same after distribution of self instructional module post test) simple random sampling technique was used to select the sample for the study. 50 primi mothers are included in the study.

RESULTS:

Finding related to pre-test, Post-test knowledge scores.

\begin{tabular}{|c|c|c|c|}
\hline $\begin{array}{c}\text { Grade of } \\
\text { Knowledge }\end{array}$ & $\begin{array}{c}\text { Range } \\
\text { of } \\
\text { score }\end{array}$ & $\begin{array}{c}\text { Pre test } \mathrm{f} \\
\%\end{array}$ & $\begin{array}{c}\text { Post test } \mathrm{F} \\
\%\end{array}$ \\
\hline $\begin{array}{l}<25 \% \\
\text { (Poor) }\end{array}$ & $<7$ & $-\quad-$ & - \\
\hline $\begin{array}{c}26-50 \% \\
\text { (Average) }\end{array}$ & $8-15$ & $\begin{array}{ll}31 & 62\end{array}$ & $-\quad-$ \\
\hline $\begin{array}{l}51-75 \% \\
\text { (Good) }\end{array}$ & $16-22$ & $\begin{array}{ll}19 & 38\end{array}$ & - \\
\hline $\begin{array}{c}76-100 \% \\
\text { (Excellent) }\end{array}$ & $23-30$ & & 2754 \\
\hline
\end{tabular}

Above table shows that in pre-test, highest percentage $(62 \%)$ of the samples had average knowledge and in post test majority (54\%) are having excellent level of knowledge. 
Effectiveness of SIM on knowledge and practice regarding new born care Mean, Mean difference, standard deviation and $t$ value on pre-test and post-test knowledge scores

\begin{tabular}{|l|l|l|l|l|}
\hline Paramet & Mea & $\begin{array}{l}\text { Standar } \\
\text { er }\end{array}$ & Mean & t"valu \\
& & $\begin{array}{l}\text { differenc } \\
\text { deviatio } \\
\text { e }\end{array}$ & e & \\
\hline Pre test & 14.1 & 3.09 & 8.5 & $\left.34.2\right|^{*}$ \\
\hline post test & 22.6 & 3.06 & - & - \\
\hline
\end{tabular}

$\mathrm{T}_{49}=2.009$

*Significant

Above table shows that the mean post-test knowledge score (22.6) was higher than the mean pre-test knowledge scores (14.1) the calculated t value $(\mathrm{t}=34.2 \mathrm{p}<0.01)$ was greater than the table value $\left(t_{49}=2.009, p<0.01\right)$ Hence the null hypothesis (H01) was rejected and the research hypothesis was accepted. The mean post-test knowledge score (22.6) was higher than then mean pre-test knowledge scores (14.1) suggesting that The SIM was effective in the knowledge of primi mothers regarding neonatal care. The mean post-test practice score (9.7) was higher than the mean pretest knowledge scores (6.64) suggesting of primi mothers regarding neonatal care. The association between the pre-test knowledge score and sleeted demographic variable was found out by using Chi square test. The data presented shows that there was no significant association between the pre-test knowledge scores and selected demographic variables.

\section{DISCUSSION:}

The nurse can create a between awareness of neonatal care among primi mother's different self instructional module can be used to important adequate knowledge of the mothers. The present study shows \& prove that the nurse can teach the mothers to the improve the knowledge about the newborn care. The nurse administrator can take part in developing protocols and standing order related to neonatal care. The nurse administrator can plan and organize training programme, to keep pace with the latest trends in neonatal care services. The investigator felt the need for conducting a true experimental study in newborn care. Research should be conduct the assess the knowledge \& practice of primi mothers regarding neonatal care.

\section{CONCLUSION:}

The overall finding of the study clearly showed that the self instructional module was significantly effective in improving the knowledge and practice scores of primi mothers regarding newborn care.

\section{BIBLIOGRAPHY:}

1. Bryce J,Black, WHO estimates of cause of death in children. Lancet 2005;365:11471152

2. Ahmad OB Lopez AD the declaine in child mortality:a rapprasial.Bull World Health Organ2007;78:1175-1191

3. Kelly D Coutts AGP early nutrition and the development of neonatas.pro nutr soc. $2000 ; 59 ; 177-185$

4. Aswathi S, Verma T; danger signs of neonatal illness; Bull World Health Organ 2006:819-826

5. WHO.Essential new born care; a report of Technical Working group Geneva World health organization 1996.

6. Young infants clinical sign study group. a multy centric study Lancet 2008;371; 135 142 
7. Baqui AH Williams EK et al Newborn care in rural Utter pradesh, Indian pediatric 2007;74:241-247

8. Mandhar D. effect of participatory intervention with women group on birth out come in napal.Lancet 2004:364;979980

9. Lewallen LP, Dick MJ, Flowers J, "Breastfeeding support and early cessation. "JOGNN2006;166-72.

10. Worku B, Kassie A. Effectiveness of early kangaroo mother care for low birth weight and preterm infants. Journal of Tropical pediatr. 2005 Apr; 51(2):93-7.
11. McGrath JM, Braesc AV. Feeding readiness in the preterm infant. Journal of perinatal Neonatal Nursing 2004 Oct-Dec;18(4): 353-68.

12. McCain GC. An evidence based guidelines for introducing oral feeding to healthy preterm infants. Neonatal Network. 2003 Sep-Oct 22(5): 45-50.

13. Pickler RH, Reyna BA. A descriptive study of bottle feeding opportunities in preterm infants. Advanced Neonatal Care 2003 Jun; 3 (3): 139-46.

14. Senath u fernadon. New born care practices at home;2009 pubmed.com

\section{ANALGESIA VS ANESTHESIA}
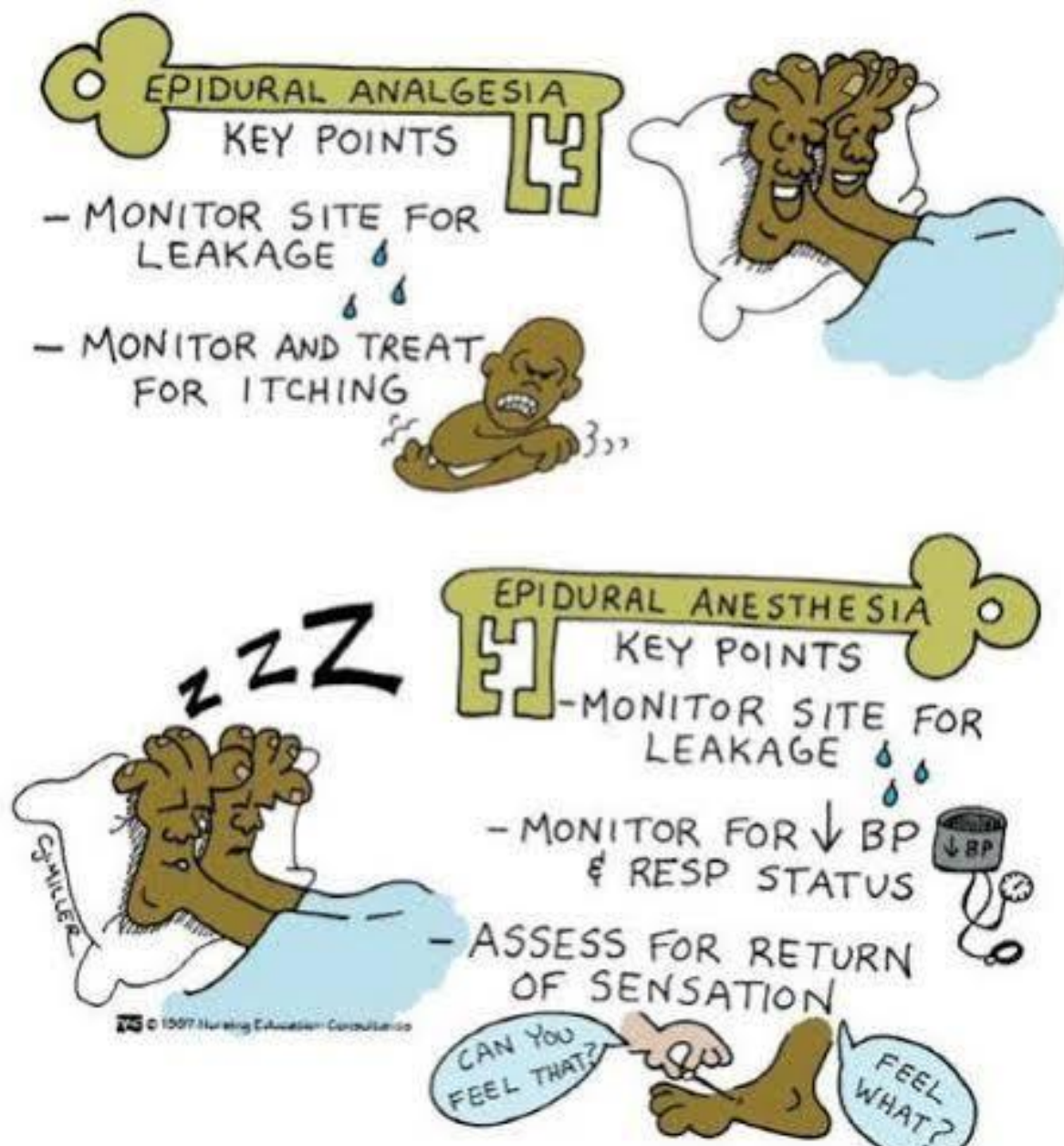